\title{
The time has come for incretins, a long time coming
}

\author{
Friedrich C. Luft
}

Received: 22 December 2009 / Accepted: 22 December 2009/Published online: 26 January 2010

(C) Springer-Verlag 2010

Therapy trials for type 2 diabetes mellitus (T2DM) present a dismal picture. Insulin and sulfonylurea drugs cause hypoglycemia and lead to weight gain; neither can inhibit heart disease. Thiazolidine diones are associated with increased heart failure. Metformin is effective, but feared because of putative side effects. Intensified treatment does not appear to help. The primary goal of the Veterans Affairs Diabetes Trial was to compare the effects of intensive and standard glucose control on cardiovascular events [1]. Moreover, intensive glucose control in patients with poorly controlled T2DM had no significant effect on the rates of major cardiovascular events, death, or microvascular complications, with the exception of progression of albuminuria. The rates of adverse events, predominantly hypoglycemia, were lower in the standard-therapy group than in the intensive-therapy group. Two other recent studies, the Action in Diabetes and Vascular Disease trial [2] and the Action to Control Cardiovascular Risk in Diabetes (ACCORD) trial [3] reported no significant decrease in cardiovascular events with intensive glucose control. The ACCORD trial ended its intensive therapy early, after 3.5 years, because of a significant increase in deaths in the intensive-therapy group. However, the novel therapies available are those that are not hampered by hypoglycemic episodes and that do not result in the 2$10 \mathrm{~kg}$ weight gain that beset the treatment arms of the above clinical trials. The incretins could offer a clinical option that could be tested today.

F. C. Luft $(\bowtie)$

Experimental and Clinical Research Center, Medical Faculty of the Charité and Max-Dclbrück Center for Molecular Medicine, Berlin-Buch, Germany

e-mail: luft@charite.de
The incretins are a group of gastrointestinal hormones that cause an increase in the amount of insulin released from the beta cell islets of Langerhans after eating, even before blood glucose levels become elevated. They also slow the rate of absorption of nutrients into the blood stream by reducing gastric emptying and may directly reduce food intake. In addition, they inhibit glucagon release from the alpha cells of the Islets of Langerhans. The major candidate molecules that fulfill criteria for an incretin are glucagon-like peptide-1 (GLP-1) and glucosedependent insulinotropic peptide (GIP). GLP-1 and GIP are inactivated by the enzyme dipeptidyl peptidase-4 (DPP-4). GLP-1 given therapeutically must be administered by continuous subcutaneous infusion. Several long-lasting GLP-1 analogs that have insulinotropic activity have been developed. Exenatide has been approved for use and liraglutide is in clinical trials. Another approach is to inhibit the enzyme that inactivates GLP-1 and GIP, namely DPP-4. Several DPP-4 inhibitors that can be taken orally as a tablet have been developed and are approved for clinical use. These drugs should enhance any effect of administered GLP-1 agonists.

In 1902, Bayliss and Starling proposed that intestinal mucosa contains a hormone that stimulates the exocrine secretion of the pancreas ("secretin"). As a matter of fact, Starling "coined" the term "hormone," which may have been his major contribution, even beyond Starling's law of the capillaries and the Frank-Starlings' principle of the heart. In 1932, La Barre proposed the name incretin for a hormone extracted from the upper gut mucosa, which caused hypoglycemia and proposed possible therapy for diabetes. Little research in this area was performed for about 30 years. In 1970, GIP Brown and colleagues isolated and sequenced GIP from intestinal mucosa. Originally named gastric inhibitory peptide, GIP was renamed 
Fig. 1 The incretins are produced by the small intestine; they stimulate insulin release from the pancreas and inhibit glucagons release (produce the "fed" state), and thereby lower blood sugar. The incretins are metabolized via dipeptidyl peptidase-4, which can be pharmacologically inhibited [7]
Incretins and their inhibition

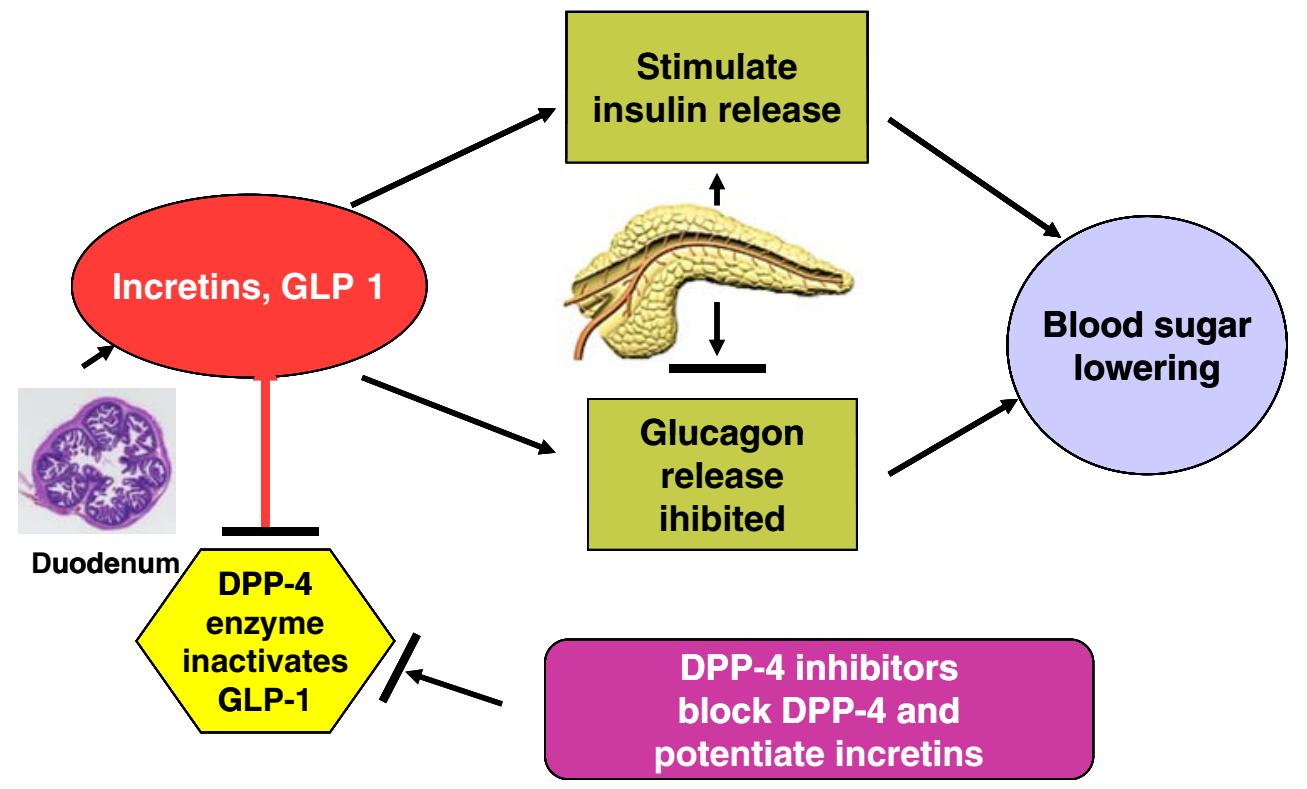

glucose-dependent insulinotropic peptide in 1973 after the same group showed that GIP stimulates insulin secretion. However, initial research could not establish its utility as a treatment for diabetes [4]. Lund and coworkers sequenced the anglerfish proglucagon peptide in 1982 [5]. Bell et al. cloned the mammalian proglucagon gene in 1983 and deduced the human proglucagon sequence [6]. Further studies on GLP-1 revealed that the entire GLP-1 molecule when administered had no effect on insulin levels. Only one specific sequence of the GLP-1 molecule has insulinotropic effects, namely the GLP-1 sequence (7-36) amide. GLP-1 (7-36) is rapidly inactivated to GLP-1 (9-36) by DPP-4 within minutes. GIP is also rapidly inactivated by DPP-4 to GIP (3-42). For details (Fig. 1), please see an excellent review by Drucker and Nauck [7].

In an earlier commentary for this journal, I discussed the use of bioengineered gut $\mathrm{K}$ cells that release glucosedependent GIP, as a novel therapy for type 1 diabetes mellitus [8] as suggested by Uniappan et al. [9]. Impetus for this commentary is the report by Liu et al. in this issue of the journal [10]. Liu et al. investigated whether or not local GLP-1 production in the intestine could differentiate intestinal progenitor cells into insulin-producing cells. They injected recombinant adenovirus bearing GLP-1 (rAd-GLP1) into the intestine of diabetic and control mice. The authors used non-obese diabetic (NOD) mice that are actually more a model for type 1 diabetes mellitus [11]. The authors found that the beta cell-differentiation transcription factors neurogenin 3 and neurogenin differentiation factor $\mathrm{D}$ (neuroD) could be detected in the intestine 2 weeks after construct injection. Blood sugar levels of the treated mice fell by 100 from $300 \mathrm{mg} / \mathrm{dl}$, while the control mice increased from 300 to $500 \mathrm{mg} / \mathrm{dl}$.

The results are in line with an earlier study by these same authors [12]. They used the same adenoviral vector rAd-GLP-1 containing the cytomegalovirus promoter/enhancer and albumin leader sequence followed by the GLP-1 cDNA. In that study, a single administration of rAd-GLP-1 via the tail vein into streptozotocin (STZ)-induced diabetic

Twenty weeks treatment for weight loss in obese participants

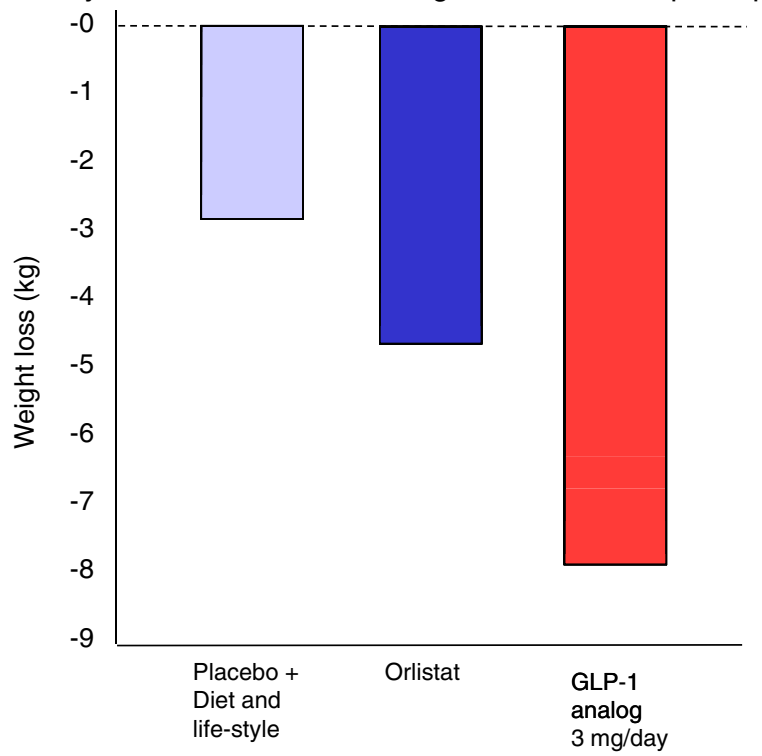

Fig. 2 Results of a randomized controlled trial, comparing a GLP-1 analog (liraglutide $3 \mathrm{mg} /$ day) to orlistat (an inhibitor of fat absorption) or to placebo (tablets and dietary counseling) on weight loss in obese patients at risk for developing T2DM [13] 
non-obese diabetic/severe combined immunodeficient (NOD/SCID) mice resulted in remission of diabetes within 10 days. In that brief experiment normoglycemia remained until the experiment was terminated. The number of insulin-positive cells in the pancreas and insulin secretion significantly increased in rAd-GLP-1-treated mice compared with STZ-induced diabetic mice treated with rAdbeta-galactosidase. The same control was included in the present study. Glucose tolerance tests in mice that achieved normoglycemia after treatment with rAd-GLP-1 showed that the kinetics of glucose clearance was similar to normal NOD/SCID mice. Treatment of autoimmune diabetic mice with rAd-GLP-1 restored normoglycemia, which was maintained for 1 year when mice were also treated with an immunoregulator to halt the autoimmune response to beta cells. With the tail-vein injection, rAd-GLP-1 was detected in pancreas, liver, spleen, heart, and lung, that is to say, "all over." In the current study, rAd-GLP-1 was placed where it belongs, that is into the duodenum. Their reasoning was that since this epithelium renews itself every week or so, the tissue should be a good source of progenitor cells. The current study indeed suggests that progenitor cells in the intestine can be coaxed into making insulin. On the basis of the two papers, the authors suggest that regeneration of insulin-producing cells by GLP-1 gene therapy may be a potential method for prolonged control of type 1 diabetes mellitus in humans.

What about T2DM? And, with the dismal results of the clinical trials, do we have any reason to believe that a GLP1-targeted strategy might do better? Indeed we have! Astrup et al. [13] performed a double-blind, placebo-controlled 20week trial, using open-label orlistat as a comparator, in 564 obese persons (body mass index $30-40 \mathrm{~kg} / \mathrm{m}^{2}$ ). The participants were randomly assigned and compared to four GLP-1 analog liraglutide or placebo. The liraglutide doses were administered once a day subcutaneously; orlistat was given three times a day orally. The participants given liraglutide lost more weight than did those on placebo, up to $7.2 \mathrm{~kg}$ compared to $2.8 \mathrm{~kg}$ with life-style placebo, and compared to $2.1 \mathrm{~kg}$ with orlistat. Beyond that result, liraglutide reduced blood pressure at all doses and lowered the prevalence of prediabetes. Thus, we already have a GLP-1-related treatment strategy for T2DM that does not lead to weight gain or increased risk of heart failure. We do not know if continuous GLP-1 therapy increases insulin production by gastrointestinal progenitor cells, but I hope so. In any event, GLP-1 therapy has been the object of many animal studies, including in the Zucker obese rat, a common model of T2DM [14].

Excitement about the experimental results presented by Liu et al. [10, 12] and the clinical results regarding liraglutide [13] involve the potential therapy of obesity without the risk of hypoglycemia (Fig. 2). Conceivably, those at risk for T2DM, persons with prediabetes and the metabolic syndrome, could be treated with GLP-1 therapy or better yet, a "gene therapy" to increase GLP-1 expression in the gastrointestinal tract. The result could be substantial weight loss and prophylaxis from T2DM. The authors of the current study should be encouraged to repeat the results in the Zucker obese rat model. The problem of vectors remains but solutions are on the horizon.

Respectfully,

Friedrich C. Luft

\section{References}

1. Duckworth W, Abraira C, Moritz T, Reda D, Emanuele N, Reaven PD, Zieve FJ, Marks J, Davis SN, Hayward R, Warren SR, Goldman S, McCarren M, Vitek ME, Henderson WG, Huang GD (2009) VADT Investigators. Glucose control and vascular complications in veterans with type 2 diabetes. N Engl J Med 360:129-139

2. The ADVANCE Collaborative Group (2008) Intensive blood glucose control and vascular outcomes in patients with type 2 diabetes. N Engl J Med 358:2560-2572

3. The Action to Control Cardiovascular Risk in Diabetes Study Group (2008) Effects of intensive glucose lowering in type 2 diabetes. N Engl J Med 358:2545-2559

4. Ross SA, Brown JC, Dupré J (1997) Hypersecretion of gastric inhibitory polypeptide following oral glucose in diabetes mellitus. Diabetes 26:525-529

5. Lund PK (2005) The discovery of glucagon-like peptide 1. Regul Pept 128(2):93-96

6. Bell GI, Santerre RF, Mullenbach GT (1983) Hamster preproglucagon contains the sequence of glucagon and two related peptides. Nature 302(5910):716-718

7. Drucker DJ, Nauck MA (2006) The incretin system: glucagonslike peptide-1 receptor agonists and dipepdidyl peptidase-4 inhbiitors in type 2 diabetes. Lancet 368:1696-1705

8. Luft FC (2009) Novel cell therapy for type 1 diabetes mellitus. J Mol Med 2009(87):659-661

9. Liu M-J, Han J, Lee Y-S, Park M-S, Shin S, Jun H-S (2010) Amelioration of hyperglycemia by intestinal over-expression of glucagons-like peptide-1 in mice. J Mol Med. doi:10.1007/ s00109-009-0571

10. Unniappan S, Wideman RD, Donald C, Gunn V, Wall JL, Zhang QX, Webber TD, Cheung AT, Kieffer TJ (2009) Treatment of diabetes by transplantation of drug-inducible insulin-producing gut cells. J Mol Med 87:703-712

11. Luft FC (2003) NOD mice get the nod. J Mol Med 81:133-134

12. Liu MJ, Shin S, Li N, Shigihara T, Lee YS, Yoon JW, Jun HS (2007) Prolonged remission of diabetes by regeneration of beta cells in diabetic mice treated with recombinant adenoviral vector expressing glucagon-like peptide-1. Mol Ther 15:86-93

13. Astrup A, Rössner S, Van Gaal L, Rissanen A, Niskanen L, Al Hakim M, Madsen J, Rasmussen MF, Lean ME, NN8022-1807 Study Group (2009) Effects of liraglutide in the treatment of obesity: a randomised, double-blind, placebo-controlled study. Lancet 374:1606-1616

14. Rodriquez de Fonseca F, Navarro M, Alvarez E, Roncero I, Chowen JA, Maestre O, Gómez R, Muñoz RM, Eng J, Blázquez E (2000) Peripheral versus central effects of glucagon-like peptide-1 receptor agonists on satiety and body weight loss in Zucker obese rats. Metabolism 49:709-717 